\title{
Effect of High Blood Pressure and Other Cardiovascular Risk Factors on All-causes Mortality in Elderly People: A Joined Survival Analysis from Brazil, Argentina and Italy
}

\author{
Liciana Vaz de Arruda Silveira ${ }^{1}$, Alberto Rubén Osella ${ }^{2}$, María del Pilar Díaz ${ }^{3}$, \\ José Eduardo Corrente ${ }^{1, *}$ \\ ${ }^{1}$ Department of Biostatistics, São Paulo State University, Botucatu, São Paulo, Brazil \\ ${ }^{2}$ Laboratory of Epidemiology and Biostatistics, National Institute of Gastroenterology, “Saverio de Bellis” Research Hospital, \\ Castellana Grotte, Italy \\ ${ }^{3}$ Biostatistics Unit, School of Nutrition, Institute of Health Sciences Research (INICSA), Universidad Nacional de Córdoba CONICET, \\ Medical Sciences College, Córdoba, Argentina
}

Copyright $@ 2019$ by authors, all rights reserved. Authors agree that this article remains permanently open access under the terms of the Creative Commons Attribution License 4.0 International License

\begin{abstract}
Non-Communicable Chronic Diseases (NCCDs) are the leading causes of ill health in elderly populations and are associated with increased risk of death. Then, the aim of this paper is to estimate the effect of High Blood Pressure on all-causes mortality among subjects aged $\geq 65$ years old in three scenarios with different socio-economic backgrounds and urbanization processes by using flexible parametric survival models. Three cohorts coming from Brazil $(\mathrm{n}=365,8$ years of follow-up), Argentina ( $n=1800,10$ years of follow-up) and Italy ( $\mathrm{n}=2472$, 30 years of follow-up) were considered and only subjects older than 64 years included. Time to death (months) from enrolment and all-causes mortality were considered. Statistical analysis included Frailty Cox's Model and Flexible Parametric Survival Analysis. Due to the two-level structure of variability (subjects nested into cohorts), multilevel mixed-effect survival regression models were fitted. For modeling purposes, only the first twelve years of follow-up were considered. Frailty Cox model showed significant positive effects of age and an effect modification of High Blood Pressure and Non-communicable diseases, but not effects proportionality. Multilevel modeling evidenced a positive statistically significant effect of Age, Non-Communicable Chronic Diseases and Smoking. There was also an effect modification of Non-Communicable Chronic Diseases on High Blood Pressure. High Blood Pressure and Non-Communicable Chronic Diseases are important causal components and strong risk factors of cardiovascular mortality in these countries.
\end{abstract}

Keywords Cardiovascular Diseases, Diabetes, Elderly,
Hypertension, Survival

\section{Introduction}

The increase in the proportion of elderly population worldwide is one of the most important demographic facts both in developed countries and developing ones ${ }^{(1,2,3)}$

Non-Communicable Chronic Diseases (NCCDs) are the leading causes of ill health in elderly populations and are associated with increased risk of death. ${ }^{(4)}$. Most common NCCDs in the elderly are Diabetes Mellitus (DM), High Blood Pressure (HBP), Cardiovascular Diseases (CVDs), Cancer, Respiratory Chronic Diseases (RCDs) and Dyslipidemia.

CVDs are the leading cause of death in developed countries and some developing ones. In many countries, CVDs mortality rates are decreasing, but the pace of this decline suggests that these diseases will still be in the future as will be their leading risk factors, namely HBP, DM, smoking and Dyslipidemia. ${ }^{(5)}$

In 2014, about 74\%, 81\% and 92\% of all deaths in Brazil, Argentina and Italy, respectively, were attributable to NCCDs, including renal diseases. ${ }^{(6,7)}$

In Brazil in $2010,7.4 \%$ of the population was $\geq 65$ years old (Aging Index 44.8) and life expectancy of 71,88 and 78,04 years for men and women, respectively. ${ }^{(8)}$ Sixteen percent of the urban population of Argentina is $\geq 65$ years old (Aging Index 46), while in rural areas, this value decreases to $10 \%$ with life expectancy of 75 and 79 years 
for men and women, respectively. ${ }^{(9)}$ In Italy, $21.4 \%$ of the population is $\geq 65$ years old with a life expectancy of 80.4 and 85 for men and women respectively (Aging Index 154.1). ${ }^{(10)}$

This work was aimed to estimate the effect of HBP on all-cause mortality among subjects with age greater than 65 years old in three scenarios with different socio-economic background and urbanization process while considering countries variability.

\section{Materials and Methods}

\subsection{Studied Population}

Three cohorts coming from Brazil, Argentina and Italy were included. Brazil: a cohort of individuals aged $\geq 60$ years old was enrolled in 2003 and followed-up until 2010 at Botucatu (São Paulo State). Botucatu is a medium-sized city $(137,899$ residents) of the most populated state $(44,035,340$ inhabitants) of Brazil. The population of Botucatu includes $8,7 \%$ of persons $\geq 65$ years old with aging index of 44.5. A two-stage random sampling was carried out and 365 subjects were enrolled. ${ }^{(11)}$

Argentina: Patients from a medical care center were enrolledin two cities of Córdoba province $(80 \%$ of its population is urban), in January 2004. Twelve percent of Córdoba population is $\geq 65$ years old (Aging Index 46). The cohort was enrolled at Córdoba city $(1,300,000$ inhabitants) and Villa Carlos Paz (62,423 inhabitants). A total of 1,142 were included in the analysis.

Italy: The study was conducted at Castellana Grotte; it has $20.4 \%$ of the population with 65 or more years old (Aging Index 154.7).Details about the cohort have been published elsewhere. $^{(12)}$ Briefly, in 1985, a systematic population random-sample of subjects $\geq 30$ years old was drawn from the electoral register: 2472 were enrolled.

A structured standard interview was conducted to collect information about socio-demographic data, health status and personal history. However, data were different among countries then, a common sub-set of information relevant to the survival was defined as time from date of enrollment to death, migration or end of study, whichever occurred first. Follow-up ended at December the 31st, 2010 in Brazil, June 30th, 2014 in Argentina and June 30th, 2015 in Italy. Time to death was set in months to one of the end-points as above. Written informed consent was obtained from all participants and the studies were conducted in/ accordance with the Helsinki Declaration. Protocols were approved by: The Research Ethical Committee of the School of Medicine, Sao Paulo State University (Brazil), The Ethical Committee of the School of Medical Sciences, University of Córdoba (Argentina) and The Technical-Scientific Review and then by the Ethical Institutional Boards of the National Institute of Gastroenterology, "Saverio de Bellis" Research Hospital

\subsection{Exposure Assessment}

Gender, age, HT, DM, smoking habit and other NCCDs were selected as covariates. Blood pressure measurements and HBP classification were made following international standards. ${ }^{(13)}$ A subject was considered as has having DM if he/she had a fast glycemia $>6.99 \mathrm{mmol} / \mathrm{L}$ or was under anti-diabetic (any) therapy. Smoking and NCCDs were defined as dichotomous variables if the subject was currently smoking or had smoked in the last five years and if he/she had CVDs, Dyslipidemia, Cancers, or RCDs, respectively.

\subsection{Tracing Procedures}

Each year a list of all deceased persons was delivered by the municipality, which the subjects belong to. After an automatized matching, each deceased person belonging to each cohort was given a date of death. Otherwise, the date of migration was delivered by the municipality.

\subsection{Statistical Methods}

Cross-tabulations between Countries and socio-demographic and survival were performed to describe the participants. Results are expressed as number of subjects $(\%)$ and mean $( \pm \mathrm{SD})$ for categorical and continuous variables, respectively.

In order to explore survival probabilities Kaplan-Meier method was applied. A Frailty Cox model was then fitted assuming gamma-distributed latent random. Main effects and effect modifications between HBP and covariates were estimated. Cox's Proportional Hazard assumption was evaluated by means of Schoenfeld residuals test (SRT).

Flexible Parametric Royston-Parmar survival models (RPM) were chosen ${ }^{(14)}$ and performed with an additional random term. ${ }^{(15)}$ Post-estimation predicted hazards by categories of HBP at 65 and 80 years old were obtained by using post-estimation tools provided by the statistical software.

All statistical analyses were performed by using Stata statistical software, version 14.1 (StataCorp LP, College Station, Texas).

\section{Results}

Participants' characteristics are shown in Table 1. Among men, more than $60 \%$ of participants were $\leq 75$ years old, without DM (except for Argentina), had HBP (except for Brazil 43.8\%), 50\% had NCCDs (except for Brazil 28.6\%) and more than 50\% were smokers for Italy.

Among women, more than $80 \%$ were $\leq 70$ years old in Italy whereas in Brazil and Cordoba about of 65\% were $\leq 75$ years old. More than $50 \%$ had not DM and had HBP. More than 50\% had not NCCDs and did not smoke (except Italy). 
Tables 1 shows that overall survival was quite different between Italy and the other two countries but homogeneous among categories of age and the Figure 1 show the smoothed hazard rate by country using Kaplan-Meier method.

Kaplan-Meier analysis evidenced statistically significant different survival for Smoking and Gender in Brazil $(p<0.01)$, NCCDs $(p<0.001)$ and Smoking $(p<0.05)$ for Argentina. By Country and Gender analysis evidenced statistically significant different survival for HBP $(p<0.05)$ for men and NCCDs for men and women $(p<0.001)$ among Argentinean. Italian women evidenced a statistically significant different survival for DM $(\mathrm{p}<0.05)$.

Frailty Cox model showed significant positive effects of age and an effect modification of HBP on NCCDs (Table 2). Cox's Model proportional hazards assumption was performed separately for each country. There was no evidence of overall non-proportionality in Brazil and Italy (SRT 3.85, $\mathrm{p}=0.697$ and SRT 2.63, $\mathrm{p}=0.854$, respectively) as opposed to Argentina (SRT 3.51, $\mathrm{p}=0.0501$ ) for DM. In mixed-effect survival regression model, unobserved variability among countries was significative (variance 1.34, 95\%CI 1.12-2.53). Mixed-effect model evidenced a positive statistically significant effect of Age, NCCDs and Smoking on All-causes Mortality. There was also an effect modification of NCCDs on HBP. (Table 2) Overall Mixed-Effect Model estimates were more conservative and precise. Fig 2 shows predicted hazard for HT for five years survival at 65 an 80 years old. Predicted Hazards for both, normal blood pressure and HBP subjects behaved in a similar way, but with different magnitude, at 65 and 80 years old in the three countries. In Brazil, predicted Hazards showed a decrease in the first twenty months of follow-up with a plateau from here on for normal blood pressure subjects whereas HBP subjects showed an increased hazard to about 15 months of follow-up with a decrease from here on. In Argentina, the predicted hazards behaved in an irregular way but with a trend to decrease from the twentieth month. In Italy, there was a steady downward trend for normal blood pressure subjects. Whereas for HT ones, this trend was evident from the twentieth month of follow-up.

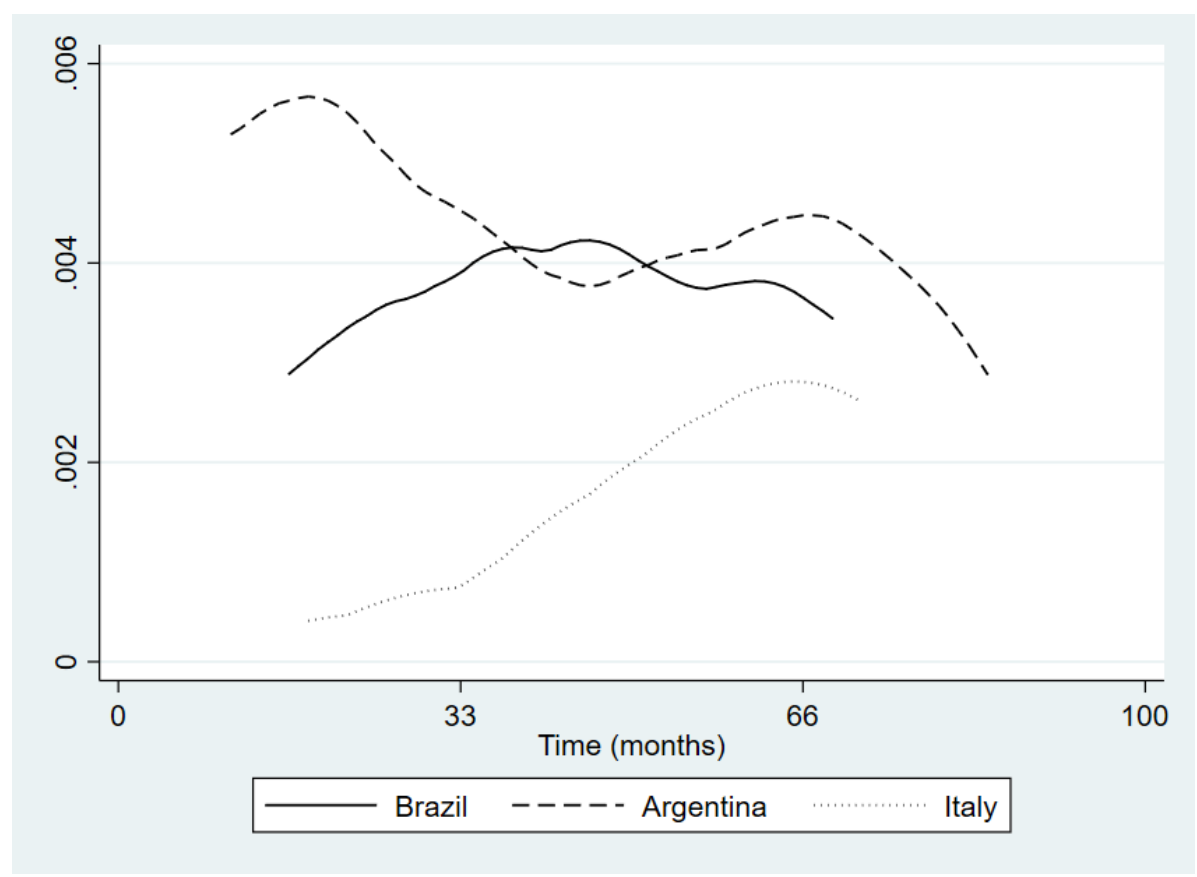

Figure 1. Smoothed Hazard Rate by Country. Botucatu (Brazil), Córdoba (Argentina) and Castellana Grotte (Italy) 
Effect of High Blood Pressure and Other Cardiovascular Risk Factors on All-causes Mortality in Elderly People: A Joined Survival Analysis from Brazil, Argentina and Italy

Table 1. Characteristics of Study Participants by Country.

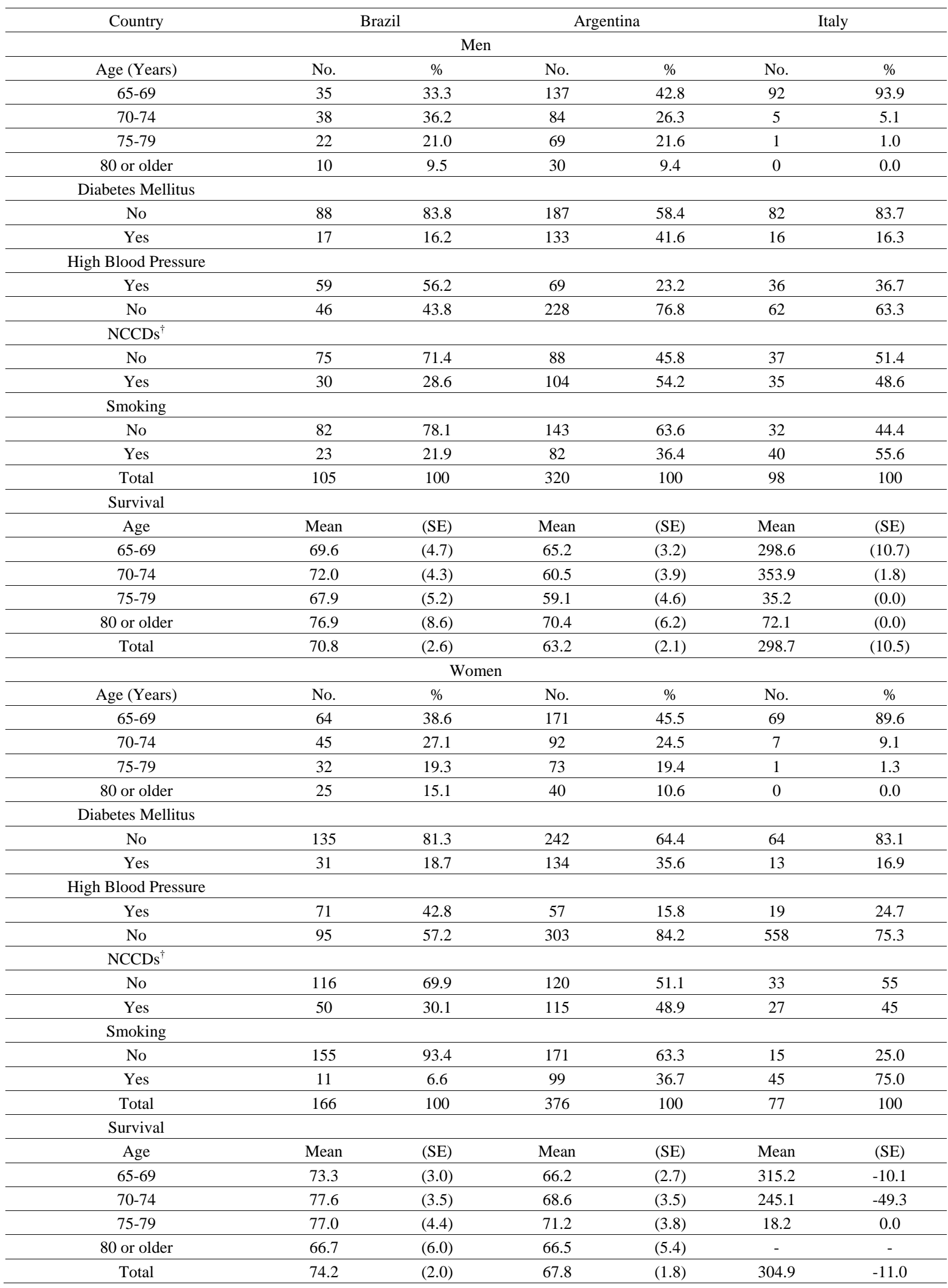

\footnotetext{
${ }^{\dagger}$ NCCDs: Non-Communicable Chronic Diseases.
} 

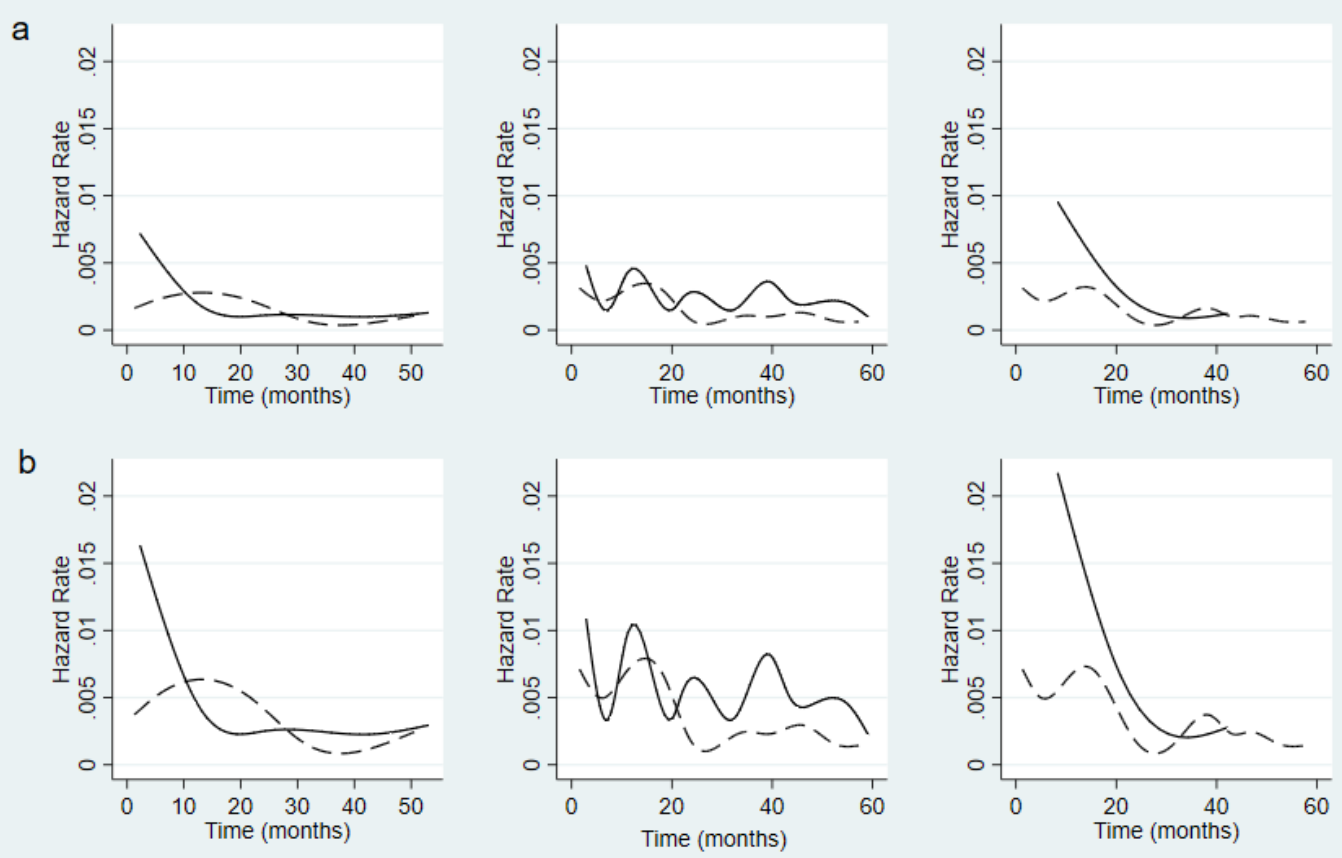

Normal Blood Pressure

- - - - High Blood Pressure

Figure 2. Hazard Rate by Country, Ages a) 65 and b) 80 years old by High Blood Pressure Status estimated using Multilevel Mixed Survival Parametric Model.

Table 2. Stratified Frailty Cox Model and Two-level Mixed Survival Parametric Model. Brazil, Argentina and Italy

\begin{tabular}{ccccc}
\hline & \multicolumn{2}{c}{ Frailty Cox Model $^{\ddagger}$} & \multicolumn{2}{c}{ Multilevel Flexible Model } \\
\hline Variable & HR & $95 \%$ CI & HR & $95 \%$ CI \\
\hline Age(continuous) & $1.04^{* *}$ & $1.01-1.08$ & $1.06^{*}$ & $1.03-1.08$ \\
\hline Sex(Female) & - & - & 0.66 & $0.43-1.13$ \\
\hline HBP(Yes) & 0.99 & $0.59-1.91$ & 1.07 & $0.61-1.87$ \\
\hline Diabetes(Yes) & 051 & $0.27-2.13$ & 0.95 & $0.54-1.66$ \\
\hline NCCDs ${ }^{\dagger}($ Yes) & $2.15^{* *}$ & $1.31-3.56$ & $2.12^{* *}$ & $1.28-3.45$ \\
\hline Smoking(Yes) & $1.77^{*}$ & $1.05-2.98$ & $1.61^{*}$ & $1.03-2.62$ \\
\hline HBP*Diabetes(Yes/Yes) & 1.95 & $0.42-2.12$ & 1.31 & $0.74-2.29$ \\
\hline HBP*NCCDs(Yes/Yes) & $4.58^{* *}$ & $1.14-18.37$ & $2.30 * *$ & $1.28-4.11$ \\
\hline HBP*Smoking(Yes/Yes) & 1.05 & $0.51-1.81$ & 1.76 & $0.89-2.46$ \\
\hline
\end{tabular}

\section{Discussion}

This study corroborates the role of Age, Smoking and NCCDs on all-causes mortality. There was also a strong effect modification of NCCDs on HBP. When Flexible mixed parametric survival model accounting for variability among countries were performed the estimates of the effects gained in validity and precision. The modelling process confirm a biological common causal model among different environments whereas maintain countries peculiarities, such as survival probabilities which remain substantially different.

HBP is a known and strong risk factor for all-causes mortality worldwide ${ }^{(16)}$ as well as some individual conditions associated such as unhealthy life-styles ${ }^{(17-19)}$. Many NCCDs share one or more common risk factors, all related to lifestyle such as smoking, hypertension, hyperglycemia, dyslipidemia, obesity, physical inactivity, and poor nutrition. ${ }^{(20)}$ Brazil and Argentina have an intermediate mortality rate for this cause and it has been shown an important reduction in life expectancy in persons aged $\geq 60$ years old when two or three conditions are present simultaneously. ${ }^{(21)}$ Moreover, a priority health index has recently identified the top priorities for NCCDs in Brazil ${ }^{(22)}$ where HBP and unhealthy life-style were the largest contributors to cardiometabolic deaths. ${ }^{(23)}$ The 
scenario remains unchanged in Argentina ${ }^{(24)}$ where HBP prevalence rate in people $\geq 65$ years old reach $71 \%$ with a different risk behavior between $\leq 55$ years old people and subjects older than 55 . $^{(25)}$

Overall, from 1998 to 2012 prevalence of some CVDs and associated risk factors has decreased in Italy ${ }^{(26)}$ and this trend has been observed in both gender and all socio-economic classes. However, there has been an increase in dyslipidemia and overweight/obesity prevalence rate. It is worthy to note that the trend for low educational class remain not favorable. By 2012, CVDs were the principal cause of death and there were more deaths in women due to HBP. ${ }^{(27)}$

Predicted HBP Hazards for each country showed differences that can be attributed not only to the different structure of the cohorts but also to local variations. Some recognized environmental factors such as urbanization and migration from rural to urban areas are correlated with HBP. Furthermore, these processes modify further the way of eating which can increase body weight. ${ }^{(28)}$ HBP predicted hazard for the Argentinean cohort showed a wavy trend. The clinical setting of that cohort may explain this trend as patients are controlled and treated for each risk factor (DM, HBP, etc.). It has been estimated that a reduction in sodium consumption currently in place in Argentina will have substantial impact in CVDS in the future. $^{(29)}$

Our estimates were different when considered as main or combined effects. In fact, HBP estimate did not reach statistical significance as reached NCCDs but their combined effect was highly significant. This effect modification is an inherent characteristic of the relationship between these two variables. Mortality associated with a single risk factor has been found to be similar but their combinations have been associated with multiplicative mortality risk and lower life expectancy. ${ }^{(30)}$

The risk factors included in the model were limited to those specifically and commonly addressed in all the cohorts. The risk factors were defined dichotomously implying a "all or none" behave which is obviously not true. Our definition of NCCDs was pragmatically settled (data availability on other diseases was not homogenous and epidemiologically motivated.).An important limitation of present study was not to include time-varying exposure information, mainly due to different managements of cohorts. Notwithstanding, the present study is an intent to assess associations among HBP, DM and other NCCDs, and survival by analyzing cohorts from different countries, which have different environmental, socio-economic and demographic conditions and health profiles.

In conclusion, HBP and NCCDs are strong risk factors for cardiovascular mortality in these countries. Estimates are conservatives and the parsimonious model obtained indicates a common causal model in three cohorts coming from very different environments.

It may be related to the advanced degree of structural heart disease and/or the antihypertensive effect of drugs for its treatment.

\section{Acknowledgements}

This study was supported by Sao Paulo Research Foundation (FAPESP Process number 2014/22856-7). Authors would like to thank all study participants for they valuable time and information. We would also like to thank to Dr. Gustavo Diaz and Bachelor Ana de la Quintana from the University of Córdoba for their collaboration with the Argentinean database.

\section{REFERENCES}

[1] Lima-Costa MF, Barreto SM, Giatti L. Health status, physical functioning, health services utilization, and expenditures on medicines among Brazilian elderly: a descriptive study using data from the National Household Survey. Reports in Public Health. 2003; (19): 735-43.

[2] Barreto, Teixeira ML, Neto MG, Duarte OL, Carmen E. The birth, life, illness, death and health care of the population over 20 years of the Unified Health System: a summary. Ministry of Health. Brazil. 2009.

[3] www.who.int/ageing/publications/global_health.pdf. Accessed November the 2nd, 2016

[4] Campolina AG, Adami F, Santos, JL, Lebrao ML. The health transition and changes in healthy life expectancy in the elderly population: possible impacts of chronic disease prevention. Reports in Public Health, 2013; (29):1217-29.

[5] Boyle JP, Honeycutt AA, Narayan KM, Hoerger TJ, Geiss $\mathrm{LS}$, Chen $\mathrm{H}$ et al. Projection of diabetes burden through 2050: impact of changing demography and disease prevalence in the U.S. Diabetes Care. 2001;(24):1936-40

[6] Schmidt MI,Duncan BB, Azevedo e Silva G, Menezes AM, Monteiro CA, Barreto SM et al. Chronic non-communicable diseases in Brazil: burden and current challenges. Lancet 2011;377(9781):P1949-1961.

[7] World Health Organization - Noncommunicable Diseases (NCD) Country Profiles, 2014. http://www.who.int/nmh/countries/. Accessed November the $4^{\text {th }}, 2016$.

[8] http://populacao.net.br. Accessed November the 3rd, 2016

[9] www.indec.gov.ar. Accessed November the 3rd, 2016

[10] ISTAT. www.istat.it Accessed November the 3rd, 2016.

[11] Tânia Ruiz, Liciana Vaz Arruda Silveira Chalita, Marilisa Berti de Azevedo Barros. Survival Study of a Sixty Year-Old and Older Cohort in Botucatu (SP) - Brazil Brazilian Journal of Epidemiology. 2003;(6): 227-36.

[12] Misciagna G. Leoci C. Elba S, Petruzzi J, Guerra V Mossa A et al. The epidemiology of cholelithiasis in southern Italy. Em J Gastroenterol Hepat.1994; (6): 937-41 
[13] Sever P. New hypertension guidelines from the National Institute for Health and Clinical Excellence and the British Hypertension Society. J Renin Angiotensin Aldosterone Syst. 2006,7(2):61-3.

[14] Royston P, Parmar MKB. Flexible parametric proportional hazards and proportional odds models for censored survival data, with application to prognostic modelling and estimation of treatment effects. Stat Med. 2002; (21): 2175-97

[15] Crowther MJ, Look MP, Riley RD. Multilevel mixed effects parametric survival models using adaptive Gauss-Hermite quadrature with application to recurrent events and individual participant data meta-analysis. Stat Med. 2014; (33):3844-58

[16] Salazar MR, Espeche WG, Aizpurua M, Leiva Sisnieguez BC, Leiva Sisnieguez CD, Dulbecco CA et al. Risk of cardiovascular disease according to blood pressure categories in an argentinean cohort. Rev Fac Cien Med Univ Nac Cordoba. 2016;73(3):181-7.

[17] Aburto NJ, Ziolkovska A, Hooper L, Elliott P, Cappuccio FP, Meerpohl JJ. Effect of lower sodium intake on health: systematic review and meta-analyses. BMJ. 2013;346: f1326. doi: 10.1136/bmj.f1326. pmid:23558163.

[18] Boeing H, Bechthold A, Bub A, Ellinger S, Haller D, Kroke A et al. Critical review: vegetables and fruit in the prevention of chronic diseases. European Journal of Nutrition 2012;51: 637-63

[19] Rossi A, Dikareva A, Bacon SL, Daskalopoulou SS. The impact of physical activity on mortality in patients with high blood pressure: a systematic review. J Hypertens. 2012;30: 1277-88

[20] Arena R, Guazzi M, Lianov L, Whitsel L, Berra K, Lavie CJ et al.Healthy lifestyle interventions to combat noncommunicable disease-a novel non-hierarchical connectivity model for key stakeholders: a policy statement from the American Heart Association, European Society of Cardiology, European Association for Cardiovascular Prevention and Rehabilitation, and American College of Preventive Medicine. Eur Heart J.2015;36(31):2097-109

[21] Rubinstein A, Colantonio L, Bardach A, Caporale J, Martí SG, Kopitowski $\mathrm{K}$ et al Estimation of the burden of cardiovascular disease attributable to modifiable risk factors and cost-effectiveness analysis of preventative interventions to reduce this burden in Argentina. BMC Public Health 2010;(10):627.

[22] Simoes EJ, Bouras A, Cortez-Escalante JJ, Malta DC, Porto DL, Mokdad AH et al.A priority health index identifies the top six priority risk and related factors for non-communicable diseases in Brazilian cities.BMC Public Health.2015;15:443

[23] Otto MC, Afshin A, Micha R, Khatibzadeh S, Fahimi S, Singh G eta al. Global Burden of Diseases, Injuries, and Risk Factors Metabolic Risk Factors of Chronic Diseases Expert Group.; Nutrition and Chronic Diseases Expert Group (NutriCoDE). The Impact of Dietary and Metabolic Risk Factors on Cardiovascular Diseases and Type 2 Diabetes Mortality in Brazil. PLoS One. 2016;11(3):e0151503.

[24] Schargrodsky H, Hernández-Hernández R, Champagne BM, Silva H, Vinueza R, Silva Ayçaguer LC et al.CARMELA: assessment of cardiovascular risk in seven Latin American cities. Am J Med.2008;121(1):58-65

[25] Diaz A, Ferrante D. Trends in prevalence of hypertension in Argentina in the last 25 years: a systematic review of observational studies. Rev. Pan Salud Pública 2015; 38(6): 496-603.

[26] Giampaoli S,Palmieri L, Donfrancesco C, Lo Noce C, Pilotto L, Vanuzzo D; Osservatorio Epidemiologico Cardiovascolare/HealthExaminationSurvey Research Group.Cardiovascular health in Italy.Ten- year surveillance of cardiovascular diseases and risk factors: Osservatorio Epidemiologico Cardiovascolare/Health Examination Survey 1998-2012. Eur J Prev Cardiol. 2015;22(2 Suppl):9-37.

[27] http://www.istat.it/it/archivio/140871. Accessed November the $7^{\text {th }}, 2016$.

[28] Ibrahim MM, Damasceno A. Hypertension in developing countries. Lancet. 2012;(380):611-9

[29] Konfino J, Mekonnen TA, Coxson PG, Ferrante D, Bibbins-Domingo K. Projected impact of a sodium consumption reduction initiative in Argentina: an analysis from the CVDS policy model. Argentina. PLoS One. 2013 Sep 9;8(9):e73824.

[30] Emerging Risk Factors Collaboration., Di Angelantonio E, Kaptoge S, Wormser D, Willeit P, Butterworth AS, Bansal $\mathrm{N}$ et al. Association of Cardiometabolic Multimorbidity With Mortality. JAMA. 2015;314(1):52-60. 